\title{
Cellular Hemoglobin Is a Useful Alternative Parameter when Lipemia Interferes with Hemoglobin Measurement
}

Byong Ho Choi ${ }^{1}$, Sung Ran $\mathrm{Cho}^{2}$, and Il Joong Park $^{2}$

${ }^{1}$ Department of Laboratory Medicine, Ajou University Hospital; ${ }^{2}$ Department of Laboratory Medicine, Ajou University School of Medicine, Suwon, Korea
Background: Saline replacement is a difficult and time-consuming procedure employed to measure hemoglobin ( $\mathrm{Hb}$ ) levels when lipaemia interferes with the accurate determination of $\mathrm{Hb}$ content. As an alternative method, we tested the reliability of cellular $\mathrm{Hb}(\mathrm{cHb})$ measurement.

Methods: Forty-eight lipemic blood samples were analysed with the LH780 (or DxH 800; Beckman Coulter Inc., USA) and ADVIA 2120i (Siemens Healthcare Diagnostics, USA) instruments. We compared the $\mathrm{Hb}$ measurements obtained following saline replacement $(\mathrm{srHb})$ with the $\mathrm{cHb}$ measurement and with the value of one-third of the hematocrit $(1 / 3 \mathrm{Hct})$. Results: The bias estimate outcomes of $\mathrm{cHb}$ with $\mathrm{srHb}$ were found to be acceptable at all medical decision points. The average difference between the value of $1 / 3 \mathrm{Hct}$ and initial $\mathrm{Hb}$, srHb, and $\mathrm{cHb}$ were $19.7 \% \pm 3.3 \%, 2.3 \% \pm 1.6 \%$, and $-0.1 \% \pm 1.1 \%$, respectively.

Conclusions: $\mathrm{cHb}$ measurements may be a feasible alternative to $\mathrm{srHb}$, when lipemia interferes with accurate $\mathrm{Hb}$ determinations.

(J Lab Med Qual Assur 2017;39:9-15)

Key Words: Interference, Hyperlipidemias, Hemoglobins

Corresponding author:

Il Joong Park

Department of Laboratory

Medicine, Ajou University School

of Medicine, 164 World cup-ro,

Yeongtong-gu, Suwon 16499,

Korea

Tel: $+82-31-219-5792$

Fax: +82-31-219-5778

E-mail: pij0304@daum.net

\section{서론}

혈색소는 적혈구를 구성하는 주요 구성성분으로, 산소 및 이 산화탄소를 운반하는 역할을 한다[1]. 혈색소의 측정은 빈혈 을 포함하는 다양한 혈액질환에서 요구되며, 현재 다양한 자 동혈구분석기에 의해 자동 측정된다[2]. 검사장비마다 약간의 차이는 있으나 특정 파장의 흡광도를 분광광도법으로 측정하 는 원리를 사용하기 때문에 고농도의 지질이나 빌리루빈에 의
한 간섭이 발생할 수 있다[2,3]. 이와 같은 간섭이 발생하면 해 결방법으로 식염수교환법을 사용하게 되는데, 식염수교환법 은 원심분리 혈장을 제거하고 동일한 양의 식염수를 첨가하여 잘 섞어준 후 다시 검사해야 하는 까다롭고 번거로운 수기를 요한다[4]. Advia 2120i (Siemens Healthcare Diagnostics, Deerfield, IL, USA)는 flow cytometry법과 2개의 다른 각을 갖는 빛 산란을 이용한 적혈구 지도를 통하여 cell hemoglobin concentration mean $(\mathrm{CHCM})$ 을 구하며 cellular hemoglobin 


\section{Journal of LABORATORY MEDICINE and QUALITY ASSURANCE}

Byong Ho Choi et al $\bullet$ Cellular Hb, a Useful Alternative Parameter of $\mathrm{Hb}$

$(\mathrm{cHb})$ 으로 계산된다. 산출과정에 흡광도법이 사용되지 않는 $\mathrm{cHb}$ 은 지질과 빌리루빈 같은 간섭물질의 영향을 받지 않는다 [2].

저자들은 Advia 2120i에서 제공되는 $\mathrm{cHb}$ 과 식염수교환법 을 통한 혈색소(saline replaced hemoglobin, srHb) 간의 교 환 가능성을 Clinical and Laboratory Standards Institute (CLSI) guideline EP09-A3에 따라 평가하여[5], cHb 값이 $\mathrm{srHb}$ 값을 대체할 수 있는지 알아보고자 한다.

\section{재료 및 방법}

\section{1. 대상 및 분석장비}

2014년 8월부터 2016년 5월까지 mean corpuscular hemoglobin concentration $(\mathrm{MCHC})$ 가 $36 \mathrm{~g} / \mathrm{dL}$ 을 초과하고 검체가 우유 빛으로 혼탁하여 고지혈 검체로 판단한 검체 48 예(MCHC의 평균士편차: $39.9 \pm 3.9 \mathrm{~g} / \mathrm{dL}$ )를 대상으로 하였 다. 해당 기간 중 식염수교환법을 시행하였던 황갈색 검체 2예 는 검체수 부족으로 제외하였다.

검사장비는 2014년 8월부터 2016년 1월까지 43예는 LH780 (Beckman Coulter Inc., Brea, CA, USA)과 Advia 2120i를, 2016년 1월부터 5월까지 5예는 DxH800 (Beckman Coulter Inc.)와 Advia $2120 \mathrm{i}$ 를 사용하였다. 본 검사실의 주 장비인 LH780 또는 DxH800으로 식염수교환법 전과 후의 혈색소, hematocrit (Hct) 및 MCHC를 측정하였고, Advia 2120i는 식염수교환법 시행 전 검체의 $\mathrm{cHb}$ 의 측정에 사용되었다.

\section{2. 식염수교환법}

대상 검체를 원심분리 $(2,265 \mathrm{~g}, 10$ 분 $)$ 후 상층 혈장을 제거 하고 동일한 양의 식염수를 첨가한 후 잘 섞는다. 이 과정을 혼 탁함이 제거될 때까지 2-3회 반복한 후 혈색소검사를 LH780 또는 DxH800으로 시행하였다.

\section{3. 바이어스검증}

CLSI guideline EP09-A3에서 제시하는 다음의 추정 바이 어스 판별기준에 따라 검증하였다[5] (Fig. 1).

1) Outcome A

바이어스의 $95 \%$ 신뢰구간이 제로 바이어스를 포함하고, 허 용 바이어스 안에 포함되는 경우로, 유의한 바이어스 없음으로 판단한다.

\section{2) Outcome B}

바이어스의 $95 \%$ 신뢰구간이 제로 바이어스를 포함하지 않 으나, 허용 바이어스 안에 포함되는 경우로, 바이어스는 적합
함으로 판단한다.

3) Outcome C

바이어스의 $95 \%$ 신뢰구간이 허용 바이어스를 벗어났으나, 바이어스의 평균은 허용 바이어스 안에 포함되는 경우로, 바이 어스는 적합함으로 판단한다.

\section{4) Outcome D}

바이어스의 평균은 허용 바이어스를 벗어났으나, $95 \%$ 신뢰 구간이 허용 바이어스에 걸친 경우로, 바이어스는 적합함으로 판단한다. 그러나 신뢰성은 outcome $\mathrm{C}$ 보다 못한 것으로 판단 한다.

\section{5) Outcome E}

바이어스의 $95 \%$ 신뢰구간이 허용 바이어스에 전혀 걸쳐있 지 않은 경우로, 부적합으로 판단한다.

판정을 위한 의학적 결정 값으로 아주대학교병원의 여성 참 고치 하한 값인 $10.7 \mathrm{~g} / \mathrm{dL}$, 남성 참고치 하한 값인 $12.5 \mathrm{~g} / \mathrm{dL}$, 여성의 진성적혈구 증가증의 기준인 $16.0 \mathrm{~g} / \mathrm{dL}$, 남성의 진성 적혈구 증가증의 기준인 $16.5 \mathrm{~g} / \mathrm{dL}$ 로 하였고[6], 허용한계치 는 $5 \%$ 를 적용하였다. 바이어스 검증은 outlier를 평가한 후 다 음 2 단계로 진행하였다. Outlier 사례는 제거한 후 다시 진행

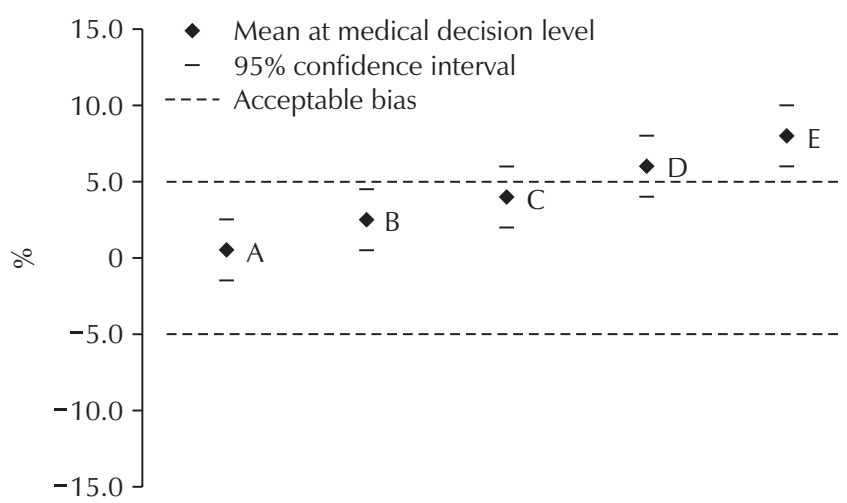

Fig. 1. Possible bias estimate outcomes of Clinical and Laboratory Standards Institute guideline EP09-A3. Outcome A: no significant bias; outcome B: the bias is acceptable; outcome C: the bias is acceptable, but an alternate conclusion that an inappropriate percentage of sample results will have bias outside the limits is also possible; outcome $\mathrm{D}$ : the bias is acceptable, but there is less confidence in this conclusion than for outcome C; outcome $\mathrm{E}$ : the performance of the candidate measurement procedure is not acceptable for the defined application. Abbreviations: MD, medical decision level; CI, confidence interval. 
하였다. 1 단계에서는 현재 권장되는 $\mathrm{srHb}$ 결과를 기준으로 초기 혈색소(initial hemoglobin, $\mathrm{iHb}$ )와 $\mathrm{cHb}$ 의 바이어스를 검증하였다. 혈색소 측정에서 지질 등의 간섭을 알려주는 지 표로 ' $\mathrm{Hb} \times 3 \neq \mathrm{Hct} \pm 3$ '의 수식이 사용된다[2]. 이는 지질 등 의 간섭을 받지 않는 측정원리를 이용하는 적혈구 수와 mean corpuscular volume (MCV)의 계산으로 산출되는 Hct(적혈 구 수 $\times \mathrm{MCV} / 10$ )도 지질 등의 간섭을 받지 않기 때문이다. 따 라서 2단계에서는 식염수교환법의 수기과정 중에 발생 가능 한 오차를 고려하여, 이러한 간섭의 영향 없이 혈색소 값을 추 정하는 Hct의 3 분의 1 값( $1 / 3 \mathrm{Hct})$ 을 기준으로 $\mathrm{iHb}, \mathrm{cHb}$ 과 $\mathrm{srHb}$ 의 바이어스를 검증하였다.

\section{4. $1 / 3 \mathrm{Hct}$ 에 대한 혈색소 지표들의 차이 평가}

각 지표들의 오차를 추정하기 위하여 앞에서 언급한 $1 / 3 \mathrm{Hct}$ 과 $\mathrm{iHb}, \mathrm{srHb}$ 및 $\mathrm{cHb}$ 의 차이의 평균 및 $95 \%$ confidence interval (CI)를 구하였다. 또한 outlier 사례의 $1 / 3 \mathrm{Hct}$ 과 $\mathrm{iHb}$, $\mathrm{srHb}$ 및 $\mathrm{cHb}$ 의 차이를 통하여 outlier 발생사유를 추정하였다.
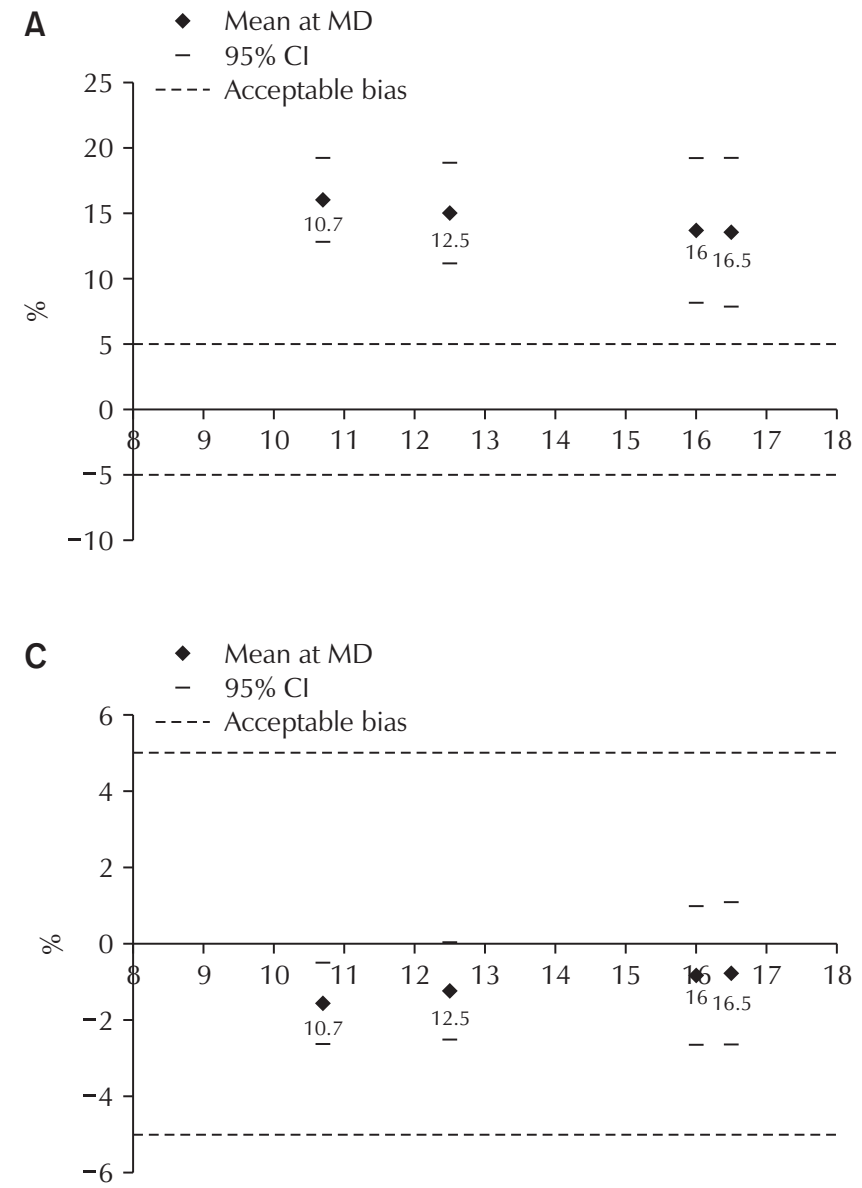

\section{결과}

\section{1. $\mathrm{srHb}$ 에 대한 혈색소 지표들의 바이어스 추정 평가}

의학적 결정 값 $10.7 \mathrm{~g} / \mathrm{dL}, 12.5 \mathrm{~g} / \mathrm{dL}, 16.0 \mathrm{~g} / \mathrm{dL}$ 및 $16.5 \mathrm{~g} /$ $\mathrm{dL}$ 에서 $\mathrm{iHb}$ 은 $\mathrm{srHb}$ 에 대해 모두 outcome $\mathrm{E}$ 인 부적합 바이어 스를 보였다. $\mathrm{cHb}$ 은 $\mathrm{srHb}$ 에 대해 의학적 결정 값 $10.7 \mathrm{~g} / \mathrm{dL}$ 및 $12.5 \mathrm{~g} / \mathrm{dL}$ 에서 outcome $\mathrm{B}$ 를, $16.0 \mathrm{~g} / \mathrm{dL}$ 및 $16.5 \mathrm{~g} / \mathrm{dL}$ 에 서 outcome $\mathrm{A}$ 로 적합한 바이어스를 보였는데, 하나의 사례가 cHb은 $9.6 \mathrm{~g} / \mathrm{dL}$ 인 반면 $\mathrm{srHb}$ 은 $11.9 \mathrm{~g} / \mathrm{dL}$ 의 결과로 outlier 로 평가되었다. Outlier 1 예를 배제한 후 $\mathrm{cHb}$ 의 $\mathrm{srHb}$ 에 대한 평가결과는 $10.7 \mathrm{~g} / \mathrm{dL}$ 에서 outcome $\mathrm{B}$ 를 보였고 $12.5 \mathrm{~g} / \mathrm{dL}$, $16.0 \mathrm{~g} / \mathrm{dL}$ 및 $16.5 \mathrm{~g} / \mathrm{dL}$ 에서 outcome A의 적합한 결과를 보 였다(Fig. 2).

\section{2. $1 / 3 \mathrm{Hct}$ 에 대한 혈색소 지표들의 바이어스 추정 평가}

의학적 결정 값 $10.7 \mathrm{~g} / \mathrm{dL}, 12.5 \mathrm{~g} / \mathrm{dL}, 16.0 \mathrm{~g} / \mathrm{dL}$ 및 $16.5 \mathrm{~g} /$ $\mathrm{dL}$ 에서 $\mathrm{iHb}$ 은 $1 / 3 \mathrm{Hct}$ 에 대해 모두 outcome $\mathrm{E}$ 인 부적합 바이 어스를 보였다. $\mathrm{srHb}$ 은 $1 / 3 \mathrm{Hct}$ 에 대해 의학적 결정 값 $10.7 \mathrm{~g} /$

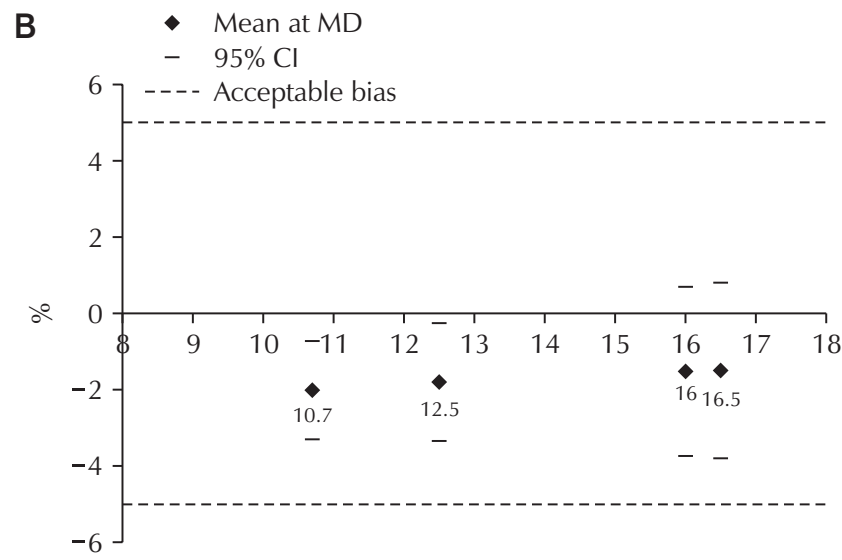

Fig. 2. Bias estimate outcome of $\mathrm{Hb}$ parameters compared with $\mathrm{srHb}$. Initial $\mathrm{Hb}$ showed unacceptable bias with $\mathrm{srHb}$ at all MDs. Cellular $\mathrm{Hb}$ showed no significant bias with srHb at three MDs and acceptable bias at one MD. (A) Initial $\mathrm{Hb}$ with srHb. (B) Cellular $\mathrm{Hb}$ with srHb before outlier elimination. (C) Cellular $\mathrm{Hb}$ with srHb after outlier elimination. Abbreviations: MD, medical decision level; CI, confidence interval; $\mathrm{Hb}$, hemoglobin; srHb, saline replaced hemoglobin. 
$\mathrm{dL}$ 및 $12.5 \mathrm{~g} / \mathrm{dL}$ 에서 outcome A를, $16.0 \mathrm{~g} / \mathrm{dL}$ 및 $16.5 \mathrm{~g} / \mathrm{dL}$ 에서 outcome $\mathrm{C}$ 의 적합한 바이어스를 보였다. $\mathrm{cHb}$ 은 $1 / 3 \mathrm{Hct}$ 에 대해 의학적 결정 값 $10.7 \mathrm{~g} / \mathrm{dL}$ 및 $12.5 \mathrm{~g} / \mathrm{dL}$ 에서 outcome $\mathrm{B}$ 를, $16.0 \mathrm{~g} / \mathrm{dL}$ 및 $16.5 \mathrm{~g} / \mathrm{dL}$ 에서 outcome $\mathrm{C}$ 의 적합한 바이 어스를 보였다(Fig. 3).

\section{3. $1 / 3 \mathrm{Hct}$ 에 대한 혈색소 지표들의 차이 평가}

$1 / 3 \mathrm{Hct}$ 과의 차이의 $95 \% \mathrm{CI}$ 는 $\mathrm{iHb}$ 에서 $19.7 \% \pm 3.3 \%$, $\mathrm{srHb}$ 에서 $2.3 \% \pm 1.6 \%, \mathrm{cHb}$ 에서 $-0.1 \% \pm 1.1 \%$ 를 보여 $\mathrm{iHb}$ 은 $\mathrm{srHb}$ 및 $\mathrm{cHb}$ 과 유의한 차이를 보였다. $\mathrm{iHb}, \mathrm{srHb}$ 및 $\mathrm{cHb}$ 의 오차한계는 각각 $3.3 \%, 1.6 \%$ 및 $1.1 \%$ 로 $\mathrm{iHb}$ 에서 가장 높 았고 $\mathrm{cHb}$ 에서 가장 낮았다. Outlier 사례의 $1 / 3 \mathrm{Hct}$ 과 $\mathrm{iHb}$ 의 차이는 $17.8 \%$ 로 $\mathrm{iHb}$ 의 $95 \% \mathrm{CI}$ 인 $19.7 \% \pm 3.3 \%$ 의 범위 안에 있었으나, $1 / 3 \mathrm{Hct}$ 과 $\mathrm{srHb}$ 의 차이는 $14.9 \%$ 로 해당 오차한계 의 9.3 배였고, $1 / 3 \mathrm{Hct}$ 과 $\mathrm{cHb}$ 의 차이는 $-5.0 \%$ 로 해당 오차한 계의 4.5 배였다(Fig. 4).
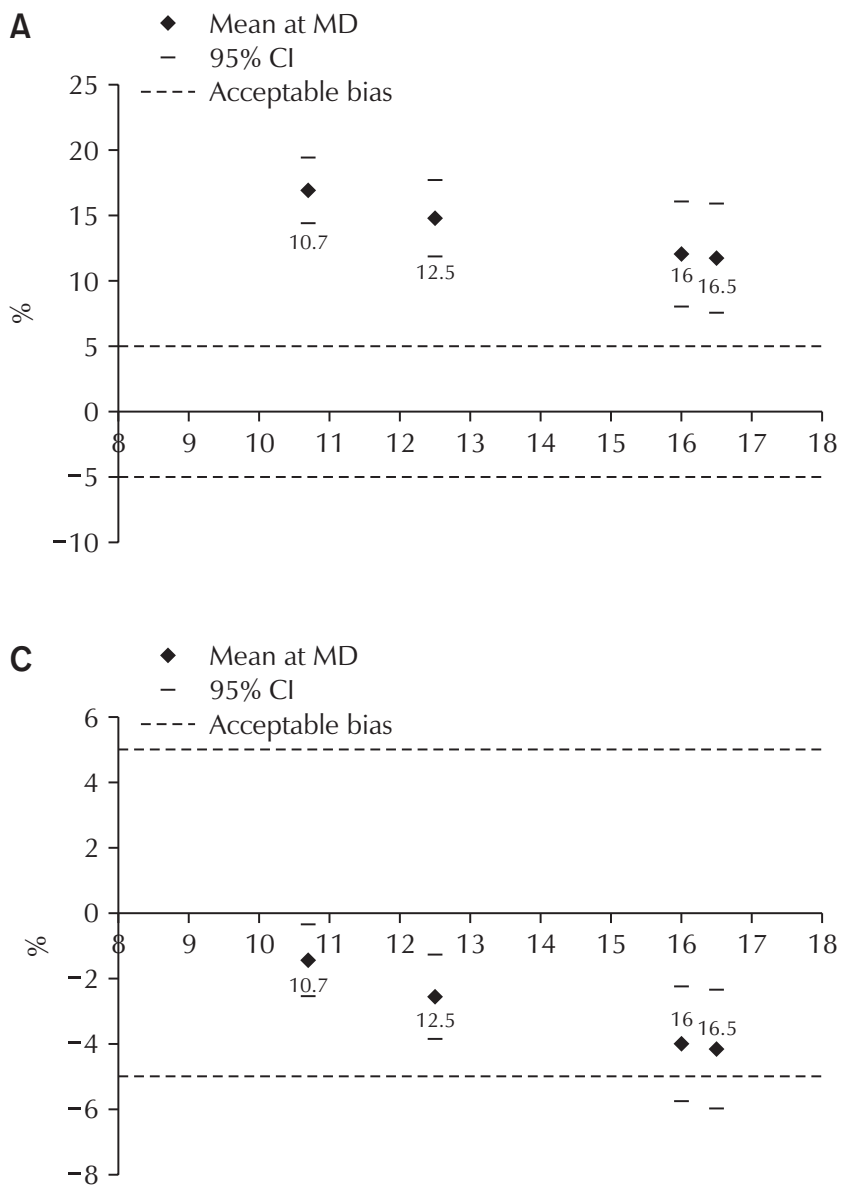

\section{고찰}

College of American Pathologists에서는 고지혈에 의해 혈 색소의 측정이 간섭받을 때 다음의 세 가지 조치를 권장한다. 첫째, 혈색소는 보고하지 않고 적혈구 용적률만 보고한다. 둘 째, 고지혈의 영향을 받지 않는 전혈 혈색소로 측정한다. 셋째, 식염수교환법을 시행한다[4].

본 연구에서도 최초의 혈색소 값은 식염수교환법을 시행한 혈색소 값과 연구자들이 정한 모든 의학적 결정 값에서 부적합 함을 보였다. 이는 고지혈 등에 의한 혈색소 검사결과가 영향 을 받는 상황에서 적합한 조치를 취하지 않고 최초의 혈색소 값이 보고된다면, 환자 진료에 부적합한 판단을 유도할 수 있 음을 보여준다. 그러나 이러한 간섭현상을 해결할 수 있는 식 염수교환법은 복잡한 절차와 주의를 필요로 하고 시행과정에 또 다른 오류를 보일 수 있다는 단점이 있다[4].

본 연구에 사용된 장비의 적혈구 지표는 직접 측정되는 지표 인 혈색소, 적혈구 수 및 $\mathrm{MCV}$ 와 측정된 지표를 사용하여 계산 되는 지표인 mean corpuscular hemoglobin $(\mathrm{MCH}), \mathrm{MCHC}$

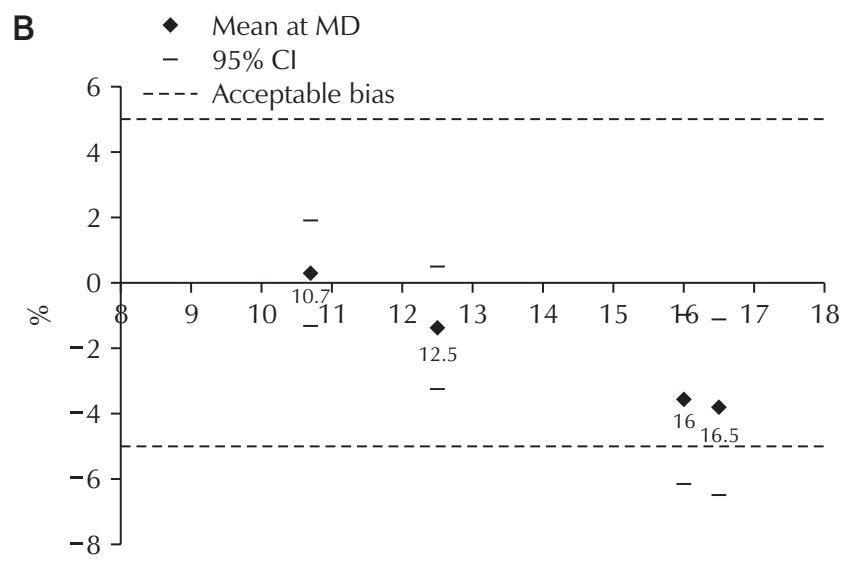

Fig. 3. Bias estimate outcome of $\mathrm{Hb}$ parameters compared with the value of $1 / 3 \mathrm{Hct}$. SrHb showed no significant bias with $1 / 3 \mathrm{Hct}$ at two MDs and acceptable bias at two MDs. Cellular $\mathrm{Hb}$ showed acceptable bias with $1 / 3 \mathrm{Hct}$ at all MDs. (A) Initial $\mathrm{Hb}$ with $1 / 3 \mathrm{Hct}$. (B) SrHb with $1 / 3 \mathrm{Hct}$. (C) Cellular Hb with $1 / 3$ Hct. Abbreviations: MD, medical decision level; $\mathrm{CI}$, confidence interval; $\mathrm{Hb}$, hemoglobin; $1 / 3 \mathrm{Hct}$, one-third of the hematocrit; srHb, saline replaced hemoglobin. 
Journal of LABORATORY MEDICINE and QUALITY ASSURANCE

Byong Ho Choi et al $\bullet$ Cellular Hb, a Useful Alternative Parameter of $\mathrm{Hb}$

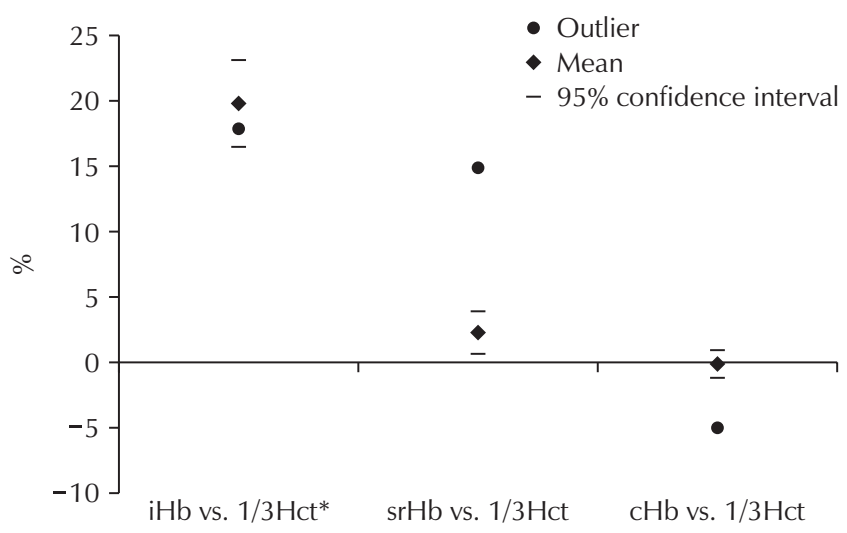

Fig. 4. Difference evaluation of $\mathrm{iHb}, \mathrm{srHb}$, and $\mathrm{cHb}$ with the value of $1 / 3 \mathrm{Hct}$. The difference between $\mathrm{iHb}$ with $1 / 3 \mathrm{Hct}$ was significantly larger than that between $\mathrm{srHb}$ with $1 / 3 \mathrm{Hct}$ and that between $\mathrm{cHb}$ with $1 / 3 \mathrm{Hct}\left({ }^{\star} \mathrm{P}<0.05\right)$. The outlier case showed a higher positive difference in terms of $\mathrm{srHb}$, but a lower negative difference in terms of $\mathrm{cHb}$. Abbreviations: $\mathrm{iHb}$, initial hemoglobin; srHb, saline replaced hemoglobin; $\mathrm{cHb}$, cellular hemoglobin; $1 / 3 \mathrm{Hct}$, one-third of the hematocrit.

및 Hct로 구분할 수 있다. 혈색소 측정은 LH780, DxH800과 Advia 2120i는 모두 modified cyanmethemoglobin법으로 시 행되며 사용되는 파장이 LH780과 DxH800은 $525 \mathrm{~nm}$, Advia $2120 \mathrm{i}$ 는 $546 \mathrm{~nm}$ 로 약간의 차이가 있다. 이러한 분광광도법의 검사원리를 사용하는 혈색소 측정은 혈액 내 고농도의 지질 등 에 의한 간섭을 피할 수 없으며[7], 혈색소 값을 사용하여 계 산되는 지표인 $\mathrm{MCH}(\mathrm{Hb}$ /적혈구 수× 10$)$ 과 $\mathrm{MCHC}(\mathrm{Hb} /$ $\mathrm{Hct} \times 100)$ 역시 간섭을 받게 된다. 반면, 적혈구 수 및 $\mathrm{MCV}$ 는 LH780과 DxH800에서는 전기저항법으로 측정되고 Advia 2120i에서는 flow cytometry법으로 측정되어 지질 등에 의한 간섭이 없으며, 계산 지표인 $\mathrm{Hct}($ 적혈구 수 $\times \mathrm{MCV} / 10)$ 역시 간섭이 발생하지 않는다[2].

Advia 2120i는 flow cytometry법과 2개의 다른 각을 갖는 빛 산란을 이용한 적혈구 지도를 통하여 $\mathrm{CHCM}$ 을 구하며, $\mathrm{CHCM}$ 은 기존 $\mathrm{MCHC}$ 에 해당된다고 할 수 있다. $\mathrm{MCHC}$ 가 앞에 언급한 것처럼 혈액 내의 지질과 빌리루빈에 간섭을 받는 것과 달리 $\mathrm{CHCM}$ 은 간섭에 영향을 받지 않는다. $\mathrm{CHCM}$ 은 일 반적으로 환자결과에 보고되지 않으나 간섭의 영향이 있을 때 $\mathrm{MCHC}$ 를 점검하는 지표로 사용될 수 있고, $\mathrm{cHb}$ 의 계산을 위 해 사용된다. 산출과정에 흡광도법이 사용되지 않는 $\mathrm{cHb}$ 은 지 질과 빌리루빈 같은 간섭물질의 영향을 받지 않는다[2].

CLSI 가이드라인은 검사방법 간 바이어스를 평가할 때 상 관계수만으로 판단하는 것이 아니라 1 차 회기방정식의 기울
기와 절편을 고려하고, 특정 결과 바이어스의 $95 \%$ 신뢰구간 과 허용하는 오차범위의 관계를 통하여 결정된 바이어스가 적 합한지 또는 부적합한지 판단한다. 또한 바이어스가 적합한 경 우에도 바이어스의 $95 \%$ 신뢰구간과 허용오차의 관계에 따라 신뢰의 차이를 부여하고 있다[5]. 본 연구에서는 $\mathrm{srHb}$ 과 $\mathrm{cHb}$ 은 $10.7 \mathrm{~g} / \mathrm{dL}$ 를 제외한 모든 의학적 결정 값에서 유의한 바이 어스가 없는 결과로 가장 우수한 교환 가능성을 보였다. 의학 적 결정 값 $10.7 \mathrm{~g} / \mathrm{dL}$ 에서도 바이어스는 적합한 결과를 보여 $\mathrm{srHb}$ 대신 $\mathrm{cHb}$ 을 사용함이 적합하다고 할 수 있었다.

식염수교환법은 원심분리, 혈장제거, 동량의 식염수 첨가 및 혼합의 과정을 반복하게 되는데 이러한 수기과정에서 오차요 인이 발생할 수 있다. 혈색소 측정에서 지질 등의 간섭을 알려 주는 지표로 ' $\mathrm{Hb} \times 3 \neq \mathrm{Hct} \pm 3$ '의 수식이 사용된다[2]. 이는 지 질 등의 간섭을 받지 않는 측정원리를 이용하는 적혈구 수와 $\mathrm{MCV}$ 의 계산으로 산출되는 $\mathrm{Hct}$ 도 지질 등의 간섭을 받지 않 기 때문이다. 본 연구에서는 $\mathrm{srHb}$ 과 $\mathrm{cHb}$ 의 오류 가능성을 평 가하기 위하여 $1 / 3 \mathrm{Hct}$ 과 $\mathrm{oHb}, \mathrm{srHb}$ 그리고 $\mathrm{cHb}$ 의 차이를 구 하였다. $1 / 3 \mathrm{Hct}$ 에 대한 $\mathrm{srHb}$ 의 차이의 오차한계는 $1.6 \%$ 로 $\mathrm{cHb}$ 의 오차한계인 $1.1 \%$ 보다 높았는데, 이는 식염수교환법에 서 발생할 수 있는 여러 오차요인에 의한 것으로 판단된다. 특 히 $\mathrm{srHb}$ 과 $\mathrm{cHb}$ 의 바이어스 평가에서 발생한 outlier 사례는 $\mathrm{srHb}$ 의 $1 / 3 \mathrm{Hct}$ 과의 차이에서 오차한계의 9.3 배를 벗어나는 차이를 보였고, 이는 식염수교환법 이후에도 간섭물질 잔류에 의한 임의오류 가능성을 보여준다고 판단된다. 그러나 $\mathrm{srHb}$ 의 $1 / 3 \mathrm{Hct}$ 에 대한 바이어스 평가는 $\mathrm{cHb}$ 보다 적은 바이어스를 보 였는데, 이는 $\mathrm{srHb}$ 의 전반적인 신뢰도가 $\mathrm{cHb}$ 보다 높을 가능 성을 보여준다고 판단된다. 혼탁물질에 의한 간섭 영향이 없이 정확한 혈색소 값을 구하는 제 3 의 방법으로 $\mathrm{srHb}$ 과 $\mathrm{cHb}$ 을 비 교한다면 어떠한 지표의 신뢰도가 높은지 확인할 수 있을 것으 로 생각된다.

본 검사실은 $\mathrm{MCHC}$ 결과가 $36 \mathrm{~g} / \mathrm{dL}$ 을 초과한 사례에서 혈 장을 육안으로 관찰하여 우유빛으로 혼탁하거나 황갈색 검체 의 경우 식염수교환법을 시행하고 있다. 그러나 식염수교환법 을 시행한 검체의 지질농도와 빌리루빈에 대한 측정은 시행하 지 않아 간섭물질의 농도에 따른 오류의 정도는 확인할 수 없 었다. 또한 본 연구기간 중 황달 검체로 판단되는 황갈색 검체 의 식염수교환법 시행 사례는 2 건이 있었으나, 황달 검체에서 식염수교환법과 $\mathrm{cHb}$ 의 교환 가능성을 평가하기에는 검체 수 가 적다고 판단하여 제외하였다. 향후 황달 검체의 추가 사례 분석을 통하여 다양한 원인에 의해 간섭받는 상황에서 식염수 교환법과 $\mathrm{cHb}$ 의 교환 가능성을 평가할 수 있을 것으로 생각된 다. 


\section{Journal of LABORATORY MEDICINE and QUALITY ASSURANCE}

Byong Ho Choi et al $\bullet$ Cellular Hb, a Useful Alternative Parameter of $\mathrm{Hb}$

결론적으로, 지질 검체에서 식염수교환법이 요구될 때, Advia 2120i를 이용한 cHb은 기존 수기인 식염수교환법을 대 체 가능하다고 생각된다. 특히 식염수교환법에서 요구되는 수 기절차를 시행하지 않아 보고시간이 단축되고, 임의오류 발생 가능성이 적으며, 검사자의 노력이 적다는 장점이 있다.

\section{REFERENCES}

1. McPherson RA, Pincus MR, Henry JB. Henry's clinical diagnosis and management by laboratory methods. 22nd ed. Philadelphia (PA): Elsevier/Saunders, 2011.

2. Keohane EM, Smith LJ, Walenga JM. Rodak's hematology: clinical principles and applications. 5th ed. St. Louis (MO): Elsevier/Saunders, 2016.

3. Bull BS. Reference and selected procedures for the quantitative determination of hemoglobin in blood: approved standard. 3rd ed. Wayne (PA): Clinical and Laboratory Standards Institute, 2000.

4. Savage RA. CAP TODAY. http://www.captodayonline. com/Archives/q_and_a/qa_07_04.html (Accessed October 21, 2016).

5. Budd JR. Measurement procedure comparison and bias estimation using patient samples: approved guideline. 3rd ed. Wayne (PA): Clinical and Laboratory Standards Institute, 2013.

6. Arber DA, Orazi A, Hasserjian R, Thiele J, Borowitz MJ, Le Beau MM, et al. The 2016 revision to the World Health Organization classification of myeloid neoplasms and acute leukemia. Blood 2016;127:2391-405.

7. Kroll MH, Elin RJ. Interference with clinical laboratory analyses. Clin Chem 1994;40(11 Pt 1):1996-2005. 
고지질혈증에서 혈색소 측정이 간섭받을 때 Celluar Hemoglobin 의 유용성

\section{최병호 ${ }^{1}$ 조성란 ${ }^{2}$ 박일중 ${ }^{2}$}

${ }^{1}$ 아주대학교병원 진단검사의학과, ${ }^{2}$ 아주대학교 의과대학 진단검사의학교실

배경: 고지질 검체와 같은 혼탁한 검체의 혈색소 측정은 힘들고 시간이 오래 걸리는 식염수교환법이 요구된다. 이에 저자들은 cellular hemoglobin $(\mathrm{cHb})$ 이 식염수교환법을 대체할 수 있는지 평가하였 다.

방법: 48개의 지질 검체를 LH780(또는 DxH800; Beckman Coulter Inc., USA) 및 ADVIA 2120i (Siemens Healthcare Diagnostics, USA) 장비로 혈색소를 측정하였다. 식염수교환법을 시행한 혈

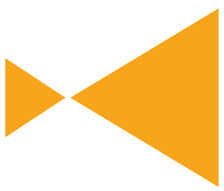

Journal of

LABORATORY MEDICINE

and

QUALITY ASSURANCE

색소(saline replaced hemoglobin, $\mathrm{srHb}$ ) 검사와 $\mathrm{cHb}$ 을 비교하였고, 적혈구 용적률의 3분의 1 값 (one-third of the hematocrit, 1/3Hct)과 비교하였다.

결과: $\mathrm{cHb}$ 의 $\mathrm{srHb}$ 과의 추정 바이어스 결과는 모든 의학적 결정 값에서 모두 적합하였다. $1 / 3 \mathrm{Hct}$ 과 혈색소 값들의 차이 평가결과는 초기 혈색소, $\mathrm{srHb}$ 및 $\mathrm{cHb}$ 이 각각 $19.7 \% \pm 3.3 \%, 2.3 \% \pm 1.6 \%$ 및 $-0.1 \% \pm 1.1 \%$ 이었다.

결론: 지질 검체에서 식염수교환법이 요구될 때, $\mathrm{cHb}$ 측정은 유용한 대체방법이 될 것으로 판단된다. (J Lab Med Qual Assur 2017;39:9-15) 